\title{
Optimization of Materials Composition and UV-VIS Light Wavelength Towards Curing Time Performance on Development of Tissue Engineering Scaffold
}

\author{
Nor Hasrul Akhmal Ngadiman 1,*(D), Md Raziff Zainal Abidin 1(D), Nur Ilyana Sahira Murizan 1(D), \\ Noordin Mohd Yusof ${ }^{1}$ (D), Ani Idris ${ }^{2}$ (D), Aini Zuhra Abdul Kadir ${ }^{1}$ (D) \\ 1 School of Mechanical Engineering, Faculty of Engineering, Universiti Teknologi Malaysia, Johor Bahru, Johor, 81310 \\ Malaysia; norhasrul@utm.my (N.H.A.N); raziff@graduate.utm.my (M.R.Z.A); nisahira2@graduate.utm.my (N.I.S.M); \\ noordin@utm.my (N.M.Y); ainizuhra@utm.my (A.Z.A.K); \\ 2 School of Chemical Engineering, Faculty of Engineering, c/o Institute of Bioproduct Development, Universiti Teknologi \\ Malaysia, Johor Bahru, Johor, 81310 Malaysia; aniidris@utm.my (A.I.); \\ * Correspondence: norhasrul@utm.my;
}

Scopus Author ID 55982418000

Received: 16.07.2020; Revised: 15.08.2020; Accepted: 16.08.2020; Published: 20.08.2020

\begin{abstract}
VAT photopolymerization 3D printing is a process that solidified a vat of liquid photopolymer resin solution into desired products in the presence of UV light. Achieving an optimal property with shorter curing time is an ultimate goal when using functional or special resins. In this study, the effect of wavelength with different compositions of UHT resin mixed PEG solution is studied. Different sources of light were identified, which is UV-A with a wavelength of $365 \mathrm{~nm}$ and VIS with a wavelength greater than $420 \mathrm{~nm}$. The PEGconcentrations were varied at $40 \%, 50 \%$, and $60 \%$. While UHT concentration ratio added into solution was $30 \%, 50 \%$, and $70 \%$. It has been observed that the optimum curing under UV and VIS wavelength were 9.55 minutes and 17.48 minutes respectively. The feasible range to optimize results of curing time, PEG $48 \%$ and UHT $41 \%$ with the result 8.6 minutes for the UV-A. Meanwhile, for VISwavelength, PEG 49\% and UHT 64\% with the result 16 minutes. The success of this study will lead to further innovation on UV-VIS light source in 3D printing in terms of energy efficiency, safety, and cost as well as further evaluation of the performance with respect to the mechanical properties of tissue engineering scaffold.
\end{abstract}

Keywords: Curing time; wavelength of lights; optimization; 3D printing.

(C) 2020 by the authors. This article is an open-access article distributed under the terms and conditions of the Creative Commons Attribution (CC BY) license (https://creativecommons.org/licenses/by/4.0/).

\section{Introduction}

3D printing is an additive manufacturing (AM) process, as opposed to the material added in layers until it takes the shape of the desired product. AM technologies include commercially available systems based on a liquid solution or VAT photopolymerization, also known as stereolithography (SLA) and digital light projection (DLP). The DLP 3D printer vat polymerization in uses a vat of liquid photopolymer resin is a model which construct specimen using layer by layer technique [1,2]. The wavelength of light is used to fill or cure the resin as needed, while a platform lifts the manufactured object up after each new layer is cured $[3,4]$. The optimum intensity level should be identified in conjunction with material property and cure cycle time during the formulation and characterization phase [5]. The polymer was cured using a reaction of the polymer with a specific wavelength from the light source. Among them, Polyethylene glycol (PEG) is one of the most widely used for tissue engineering applications 
due to the extreme hydrophilicity and biocompatibility of this polymer and resulting hydrogel [6]. Poly(ethylene glycol) (PEG)-based hydrogels are structural can be crosslinked by modifying each end with acrylates or methacrylates [7-9].

This study explores the possibility of using various mixtures, which consist of different combinations of standard photopolymer (UHT) resin and polyethylene glycol (PEG) solution in terms of the optimization towards a curing time. The wavelength of light plays an important role in the curing process, which gives an effect on the properties of the developed scaffold [10-12]. Different input setting parameters and types of resin used will give a different response on the cured thickness of solidified resin, mechanical properties, biocompatibility, and porosity of scaffold [13-15]. The roles of the process and materials are summarized in Table 1. In addition, the use of VIS light is safe, convenient, and reduces the risks due to UV radiation exposure that may harm our body [16]. It is also energy efficient and important to evaluate the different wavelengths in 3D prints curing in order to get optimum conditions [17]. A previous study was evaluated that different wavelengths will have different effects on the curing time [18]. The fabricated UV-VIS chamber lightbox was then tested for its function in experiment design.

Table 1. Role of the process and materials.

\begin{tabular}{l|l|l} 
No & Item & Role \\
\hline 1 & UV-VIS chamber lightbox & $\begin{array}{l}\text { Material is convection heated and automatically rotated in lightbox } \\
\text { reflective chamber to ensure a consistency cure. }\end{array}$ \\
\hline 2 & Polyethylene glycol (PEG) & As based material, biocompatibility. \\
\hline 3 & $\begin{array}{l}\text { Commercially available Ultra Hard and } \\
\text { Tough (UHT) resin }\end{array}$ & $\begin{array}{l}\text { Photopolymer resins that react with UV light and bind PEG to form a } \\
\text { hydrogel solution. }\end{array}$ \\
\hline 4 & UVA and VIS & To use during the curing process.
\end{tabular}

\section{Materials and Methods}

\subsection{Materials.}

This study was used two different light sources consists of 36Watt UV nail cure and 36Watt fluorescent light to cure a PEG and UHT solution. The chemical used, Dimethyl sulfoxide (DMSO), polyethylene glycol (PEG200) $\mathrm{HO}\left(\mathrm{C}_{2} \mathrm{H}_{4} \mathrm{O}\right) \mathrm{nH}$, Ultra Hard and Tough (UHT) resin.

\subsection{Preparation of PEG solution, PEG, and UHT mixture.}

To prepare a composite solution for tissue engineering, there are a few steps involved. The material used, such as Polyethylene Glycol (PEG) and Ultra Hard and Tough (UHT), are identified for this study. Both are in liquids solution; the mixed-up chemically could result in the reaction. In addition, PEG needs to be dissolved first with Dimethyl Sulfoxide (DMSO), which acts as a solvent to dissolve PEG as well as to vary the percentage concentration of PEG solution. In this study, PEG solution concentration to be used is $40 \%, 50 \%$, and $60 \% \mathrm{v} / \mathrm{v}$. To produce a $40 \% \mathrm{v} / \mathrm{v}$ PEG concentration, $40 \mathrm{ml}$ of PEG is dissolved with $100 \mathrm{ml}$ DMSO. The same step repeated for others concentration by varying the volume of PEG used. After that, UHT resin is added into the PEG solution with $30 \%, 50 \%$, and $70 \%$ of ratio concentration.

\subsection{Design of experiment (DOE).}

The design of experiments (DOE) is a systematic method to determine the relationship between factors affecting a process and the output of that process. In other words, it is used to 
find cause-and-effect relationships. The outcome of this experiment will be to suggest which condition setting is optimum curing time of the composites. For this study, the purpose DOE was used as a tool for the optimization process. An optimization design is necessary to determine the true cause of the curvature. It is used to find the factor settings that will allow the system to meet or exceed specified goals. The experimental design has been developed of two full factorials, with three factors was involved.

\subsubsection{Factors and level identification.}

In 3D printing, polymers curing and crosslinking are highly dependent on various variables. Among them, the significant factors of the curing process reflex on wavelength spectra. Different wavelength was triggered the amount of polymers crosslinks and curing time. In this study, the wavelength of light chosen was UVA and VIS fluorescent. Materials identified PEG and UHT were based on its reform hydrogel in tissue engineering previously. Table 2 shows the selection range of parameters. Hence, the DOE was conducted based on the chosen parameters. Two parameters selected will be run at two levels, namely L [1] as low level and L [2] as a high level in numeric. Another one variable represents a categorical factor. The synthesized PEG and UHT towards curing time were performed in the optimization process of the experimental design.

Table 2. Selection factors and levels.

\begin{tabular}{l|l|l|l|l} 
Factors & Name & Levels & L[1] & L[2] \\
\hline A [Numeric] & PEG concentration & N/A & 40 & 60 \\
\hline B [Numeric] & UHT ratio concentration & N/A & 30 & 70 \\
\hline C [Categoric] & Wavelength & 2 & UV & VIS
\end{tabular}

\subsubsection{Experimental matrix design.}

There are two main types of variables, independent and dependent variables. An independent variable is a variable that is changed or controlled in an experiment to test the effects on the dependent variable. A dependent variable is a variable being tested and measured, also called a response. The experiment builds a desired number of runs, and the proposed parameter setting for each factor has been entered into experiment design. The PEG concentration and UHT concentration ratio mixtures were the composite factors that be cured under UV-VIS wavelength and the experiment response towards a curing time.

By using two full factorial designs with each factor at two levels, the number of runs that have been conducted was 8 treatment combinations $\left(2^{3}=8\right)$. Table 3 shows the optimization design of this study consist of 23 number of runs randomly with 4 center points. Design-Expert software version 11 has been used for the analysis. Design expert is a piece of software designed to help with the design and interpretation of multi-factor experiments. It offers numerous classes of design.

\subsubsection{Data analysis.}

Analysis of Variance (ANOVA) is a statistical method used to test differences between two or more means. ANOVA was done using Design-Expert software following the data of the experiment. The factors, PEG and UHT mixture concentration and response towards curing time, then analyze. Normal probability, power transformation, residual plot, contour plot has been obtained from the software. An optimal setting was suggested by the response optimization program. 
Table 3. Optimization design matrix.

\begin{tabular}{l|l|l|l} 
No & Factor 1 & Factor 2 & Factor 3 \\
\hline Run & A: PEG concentration & B: UHT ratio concentration & C: Wavelength \\
\hline 1 & 60 & 70 & VIS \\
\hline 2 & 50 & 70 & UV \\
\hline 3 & 50 & 50 & VIS \\
\hline 4 & 60 & 30 & UV \\
\hline 5 & 50 & 50 & VIS \\
\hline 6 & 50 & 50 & UV \\
\hline 7 & 50 & 50 & UV \\
\hline 8 & 60 & 70 & VIS \\
\hline 9 & 50 & 50 & VIS \\
\hline 10 & 40 & 30 & VIS \\
\hline 11 & 50 & 50 & VIS \\
\hline 12 & 60 & 30 & VIS \\
\hline 13 & 50 & 50 & UV \\
\hline 14 & 40 & 70 & UV \\
\hline 16 & 60 & 70 & UV \\
\hline 17 & 60 & 50 & UV \\
\hline 18 & 50 & 30 & VIS \\
\hline 19 & 40 & 30 & UV \\
\hline 20 & 60 & 70 & VIS \\
\hline 22 & 40 & 30 & UV \\
\hline 23 & 50 & 50 & UV \\
\hline & 50 & VIS \\
\hline
\end{tabular}

2.3.4. Validity.

The confirmation run in order to verify the observed value to compare with predicted value from the equation model was collected. In this study, four (4) samples were randomly selected with two (2) samples were UV cured, and the other two (2) samples were cured with VIS light. The percentage calculated must be less than $10 \%$ to be considered a success. Percent error formula, as shown in equation (1). The experimental value is obtained from the observation result and theoretical value from the predicted equation obtained during the ANOVA analysis.

$$
\frac{\text { Experimental-Theoretical }}{\text { Theoretical }} \times 100 \%
$$

\section{Results and Discussion}

The collected data from DOE has been analyzed by using Design-Expert software. Related analysis such as normal probability plot, analysis of variance (ANOVA), 3D surface graph and contour plot, residual plots, towards a response which is curing time has been obtained. Table 4 shows the observation result of the optimization design. Based on the result, the shortest curing time was 8.98 minutes and a concentration of 50\% PEG into 50\% UHT ratio concentration mixture cured under UV. In contrast, the longest curing time was 129 minutes consists of $60 \%$ PEG into $30 \%$ UHT ratio concentration cured under VIS.

\subsection{Power transformation.}

In this study, the observed response ratio max over min value more than 10 , and the design transformation was required in order to make data normality and fit for the design analysis. One of the methods for converting data to follow a normal distribution is the BoxCox power transformation method. The Box-Cox plot is a tool to determine the most appropriate power transformation to apply to the response data. Figure 1 shows the minimum 
lambda values are -0.5 , as well as lambdas at the $95 \%$ confidence range $(\lambda=-0.56)$, and the current power transformation recommended fits for $\lambda=-0.5$ was inverse square root.

Table 4. Experimental result.

\begin{tabular}{l|c|c|c|c} 
& Factor 1 & Factor 2 & Factor 3 & Response \\
\hline Run & A: PEG concentration & B: UHT ratio concentration & C: Wavelength & Curing time \\
\hline 1 & $\%$ & $\%$ & nm & Minutes \\
\hline 2 & 60 & 70 & VIS & 18.53 \\
\hline 3 & 50 & 70 & UV & 19.49 \\
\hline 4 & 50 & 50 & VIS & 19.12 \\
\hline 5 & 60 & 30 & UV & 10.85 \\
\hline 6 & 50 & 50 & VIS & 18.78 \\
\hline 7 & 50 & 50 & UV & 9.02 \\
\hline 8 & 50 & 50 & VIS & 8.98 \\
\hline 9 & 60 & 70 & VIS & 19.45 \\
\hline 10 & 50 & 50 & VIS & 19.03 \\
\hline 11 & 40 & 30 & VIS & 20.45 \\
\hline 12 & 50 & 50 & VIS & 129 \\
\hline 13 & 60 & 30 & UV & 9.32 \\
\hline 14 & 50 & 50 & UV & 19.48 \\
\hline 15 & 40 & 70 & UV & 22.08 \\
\hline 16 & 60 & 70 & UV & 10.15 \\
\hline 17 & 60 & 50 & VIS & 117 \\
\hline 18 & 50 & 30 & UV & 9.87 \\
\hline 19 & 40 & 30 & VIS & 18.27 \\
\hline 20 & 40 & 70 & UV & 10.21 \\
\hline 21 & 60 & 30 & UV & 9.72 \\
\hline 22 & 40 & 50 & VIS & 21.83 \\
\hline 23 & 40 & 50 & UV & 9.35
\end{tabular}

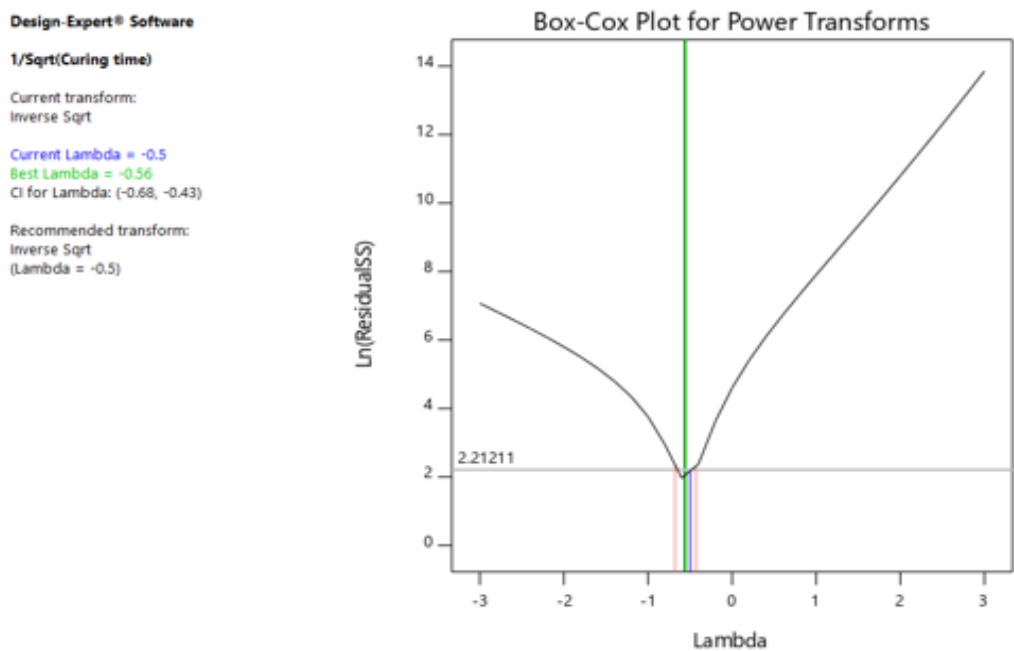

Figure 1. Box-Cox transformation plot.

\subsection{ANOVA.}

In Design-Expert, a variety of statistical tables is provided, which can be used to identify a suitable model for further in-depth study. Table 5 shows the sequential sum of the square. Analysis of variance typically looks at the p-values to determine if the model explains a significant portion of the variance. The $\mathrm{p}$-value is the level of marginal significance within a statistical hypothesis test representing the probability of the occurrence of a given event [19]. Whereas the $\mathrm{F}$ value represents the value of the $\mathrm{F}$ distribution, which is to be used in determining the significance of the test. The full-order model that meets the criteria is labeled as "Suggested". 
Table 5. The sequential sum of the square.

\begin{tabular}{|c|c|c|c|c|c|c|}
\hline Source & Sum of Squares & df & Mean Square & F-value & p-value & \\
\hline Mean vs Total & 1.38 & 1 & 1.38 & & & \\
\hline Linear vs Mean & 0.0673 & 3 & 0.0224 & 6.83 & 0.0026 & \\
\hline 2FI vs Linear & 0.0411 & 3 & 0.0137 & 10.30 & 0.0005 & \\
\hline Quadratic vs 2FI & 0.0210 & 2 & 0.0105 & 601.83 & $<0.0001$ & 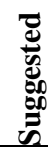 \\
\hline $\begin{array}{ll}\text { Cubic } & \text { vs } \\
\text { Quadratic }\end{array}$ & 0.0001 & 5 & 0.0000 & 0.5148 & 0.7595 & 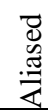 \\
\hline Residual & 0.0002 & 9 & 0.0000 & & & \\
\hline Total & 1.51 & 23 & 0.0658 & & & \\
\hline
\end{tabular}

From the table, the highest F-value is recorded when the quadratic terms are added to the 2FI model (Quadratic vs. 2FI). It shows that this model is the most significant. In addition, a small p-value also specifies that the addition of quadratic terms has enhanced the model. Selection of the highest order polynomial where are the additional terms are significant, and the model is not aliased. The design model of the optimization experimental with the highest polynomial was suggested quadratic.

\subsection{ANOVA table.}

An ANOVA table has been generated during the study, and the test result, as shown in Table 6.

The Model F-value of 925.52 implies the model is significant. There is only a $0.01 \%$ chance that an F-value this large could occur due to noise. P-values less than 0.0500 indicate model terms are significant. In this case, $\mathrm{A}, \mathrm{B}, \mathrm{C}, \mathrm{BC}, \mathrm{A}^{2}, \mathrm{~B}^{2}$ are significant model terms. Values greater than 0.1000 indicate the model terms are not significant.

If there are many insignificant model terms (not counting those required to support hierarchy), model reduction may improve your model. The Lack of Fit F-value of 0.82 implies the Lack of Fit is not significant relative to the pure error. There is a $58.66 \%$ chance that a Lack of Fit F-value this large could occur due to noise. Non-significant lack of fit is good and wants the model to fit.

Table 6. ANOVA for the quadratic model.

\begin{tabular}{|c|c|c|c|c|c|c|}
\hline Source & Sum of Squares & df & Mean Square & F-value & p-value & \\
\hline Model & 0.1294 & 8 & 0.0162 & 925.52 & $<0.0001$ & 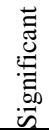 \\
\hline A - PEG concentration & 0.0001 & 1 & 0.0001 & 6.73 & 0.0212 & \\
\hline B - UHT concentration ratio & 0.0018 & 1 & 0.0018 & 104.25 & $<0.0001$ & \\
\hline C - Wavelength & 0.0610 & 1 & 0.0610 & 3490.23 & $<0.0001$ & \\
\hline $\mathrm{AB}$ & $8.343 \mathrm{E}-06$ & 1 & $8.343 \mathrm{E}-06$ & 0.4775 & 0.5009 & \\
\hline $\mathrm{AC}$ & 0.0000 & 1 & 0.0000 & 2.53 & 0.1338 & \\
\hline $\mathrm{BC}$ & 0.0378 & 1 & 0.0378 & 2163.91 & $<0.0001$ & \\
\hline $\mathrm{A}^{2}$ & 0.0004 & 1 & 0.0004 & 21.72 & 0.0004 & \\
\hline $\mathrm{B}^{2}$ & 0.0107 & 1 & 0.0107 & 611.72 & $<0.0001$ & \\
\hline Residual & 0.0002 & 14 & 0.0000 & & & \\
\hline Lack of Fit & 0.0001 & 6 & 0.0000 & 0.8158 & 0.5866 & 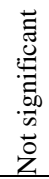 \\
\hline Pure Error & 0.0002 & 8 & 0.0000 & & & \\
\hline Cor Total & 0.1296 & 22 & & & & \\
\hline
\end{tabular}


- Prediction equation model for UV wavelength $\frac{1}{\sqrt{\text { curing time }}}=-0.145918+0.010304 \times P E G \%+0.011618 \times U H T \%-(4.74135 E-$ 06) $\times P E G \% \times U H T \%-0.000106 \times P E G \%^{2}-0.000137 \times U H T \%^{2}$

- Prediction equation model for VIS wavelength

$\frac{1}{\sqrt{\text { curing time }}}=-0.569543+0.010688 \times P E G \%+0.017611 \times U H T \%-(4.74135 E-$ 06) $\times P E G \% \times U H T \%-0.000106 \times P E G \%^{2}-0.000137 \times U H T \%^{2}$

The equation in terms of actual factors can be used to make predictions about the response for given levels of each factor. The equation (2) and equation (3) in this study were applicable prediction equation model of a factor UV and VIS wavelength, respectively.

\subsection{Diagnostics.}

\subsubsection{Residual vs. run.}

Residual vs. run is a plot of residuals versus the observed run order. It checks for lurking variables that may have influenced the response during the experiment. Ideally, the residuals on the plot should fall randomly around the centerline in, as shown in Figure 2.

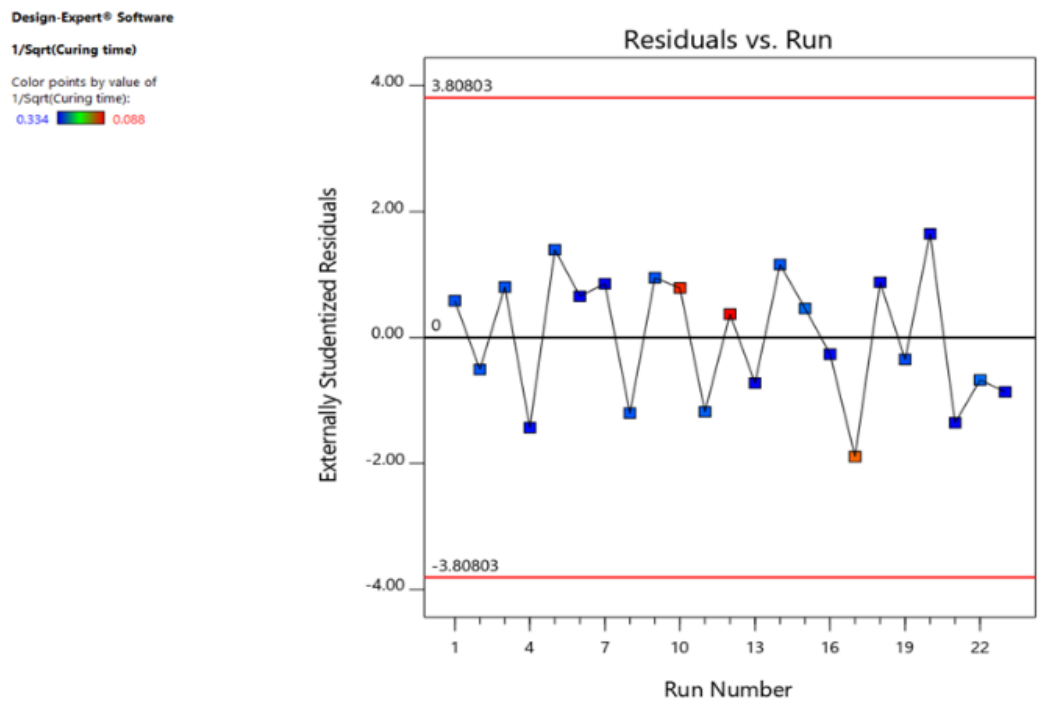

Figure 2. Residual vs. run plot.

Trends indicate a time-related variable lurking in the background. Blocking and randomization provide insurance against trends ruining the analysis so-called an outlier.

\subsubsection{Normal probability plot.}

The normal probability plot indicates whether the residuals follow a normal distribution, thus follow the straight line. Ideally, the normal plot of residuals is a straight line, indicating no abnormalities. In this study, the data did not have to match up perfectly with the line in, as shown in Figure 3. A good rule of thumb is called the "fat pencil" test was performed. As a plot test, a fat pencil over the line and it covers up all the data points, and the data were sufficiently normal. In this case, the plot had no issue, so we can proceed with the other analysis. 


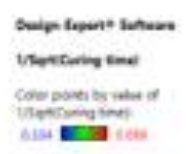

1

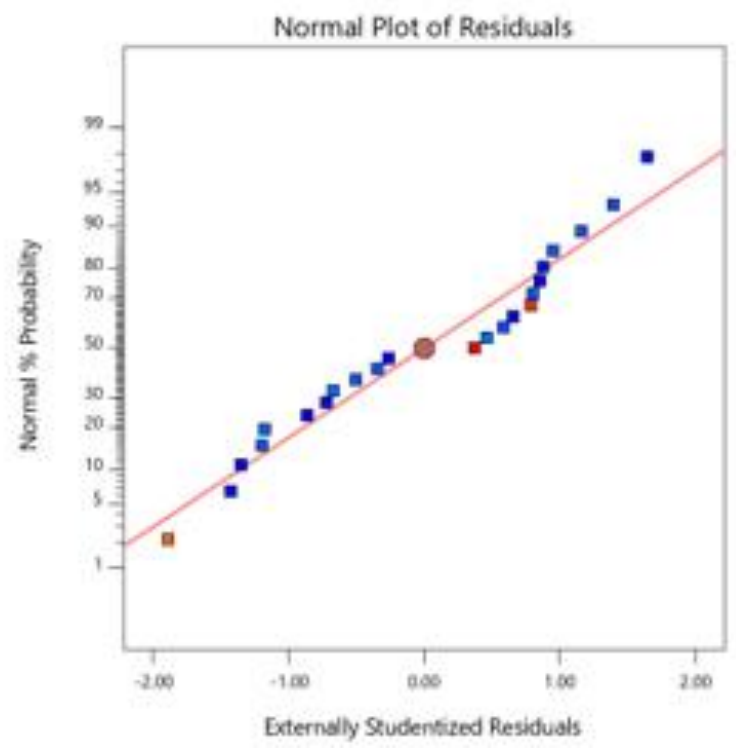

Figure 3. Normal probability plot.

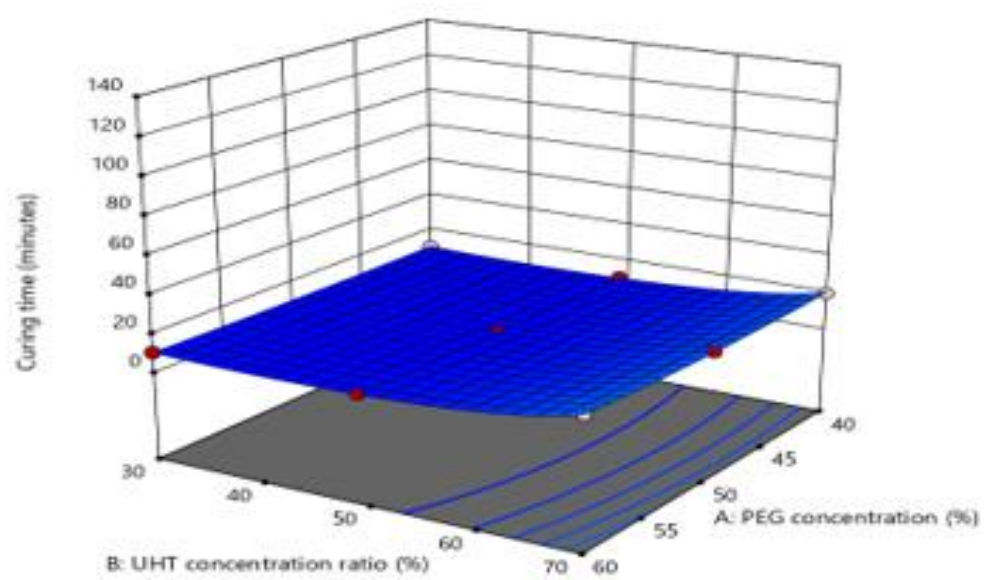

Figure 4. 3D plot UV light source design points.

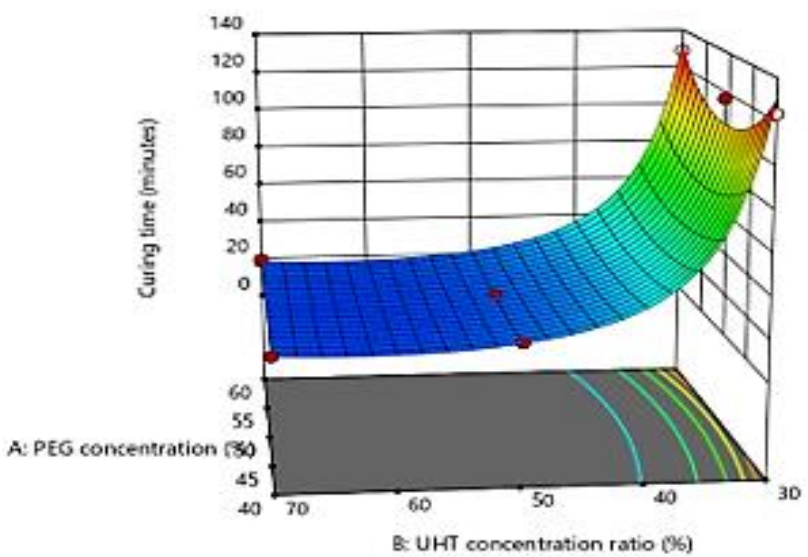

Figure 5. 3D plot VIS light source design points.

\subsubsection{D surface.}

The 3D Surface plot is a projection of the contour plot giving shape in addition to the color and contour. The plot show details about the prediction. It provides a visual reference to see the differences in the outcomes when the factors are categoric in nature. It is the interaction plot given depth in addition to the color. 
Figure 4 and Figure 5 show the best angle for the 3D surface plot UV and VIS that have been interpreted from the Design-Expert. The response, curing time of the ultraviolet light (UV) wavelength as an actual factor. Where the UHT concentration ratio between $50 \%$ to $70 \%$ indicates that the result slightly increasing in curing time.

The curing time of the visible light (VIS) wavelength factor gives the longest time is colored in red, which is falls at $30 \%$ UHT ratio concentration.

\subsection{Optimization solution.}

Solutions for 2 combinations of categorical factor levels, as shown in Table 7. The desirability of 1.00 means the goals were easy to reach, and better results may be available. Consider making the goals more difficult or adding new criteria for less critical responses and even factors [19].

The ultimate goal is not to maximize the desirability value. The factor settings that result in the highest desirability scores indicate there is an island of acceptable outcomes. It is quite possible for there to be multiple islands (local optima) to explore.

Table 7. UV-VIS curing time optimization solution.

\begin{tabular}{c|c|c|c|c|c|c} 
No & $\begin{array}{c}\text { PEG } \\
\text { concentration }\end{array}$ & $\begin{array}{c}\text { UHT concentration } \\
\text { ratio }\end{array}$ & Wavelength & $\begin{array}{c}\text { Curing time* } \\
\text { (Predicted) }\end{array}$ & Desirability & $\begin{array}{c}\text { Desirability } \\
\text { (w/o Intervals) }\end{array}$ \\
\hline 1 & 47.773 & 41.204 & UV & $\begin{array}{c}0.341 \\
(8.6 \mathrm{~min})\end{array}$ & 0.030 & 1.000 \\
\hline 2 & 48.993 & 63.617 & VIS & $\begin{array}{c}0.250 \\
(16 \mathrm{~min})\end{array}$ & 0.010 & 0.658
\end{tabular}

Based on the design result, it clearly states that the best curing time combinations of categories factor levels between UV and VIS. UV wavelength curing is synthesized the composite $48 \%$ of PEG concentration added with $41 \%$ of UHT concentration ratio. On the other hand, VIS wavelength is synthesized the composite $49 \%$ of PEG concentration and $64 \%$ of UHT ratio concentration. Then compositions of the solution had confirmed in experimental, and the result was compared, as shown in Table 8.

Table 8. Factors level of optimization solution.

\begin{tabular}{l|c|c|c|c|c} 
Number & $\begin{array}{c}\text { PEG } \\
\text { concentration }\end{array}$ & $\begin{array}{c}\text { UHT concentration } \\
\text { ratio }\end{array}$ & Wavelength & $\begin{array}{c}\text { Curing time* } \\
\text { (predict) }\end{array}$ & $\begin{array}{c}\text { Experimental Curing } \\
\text { Time }\end{array}$ \\
\hline 1 & 47.773 & 41.204 & UV & $\begin{array}{c}0.341 \\
(8.6 \mathrm{~min})\end{array}$ & $9.55 \mathrm{~min}$ \\
\hline 2 & 48.993 & 63.617 & VIS & $\begin{array}{c}0.250 \\
(16 \mathrm{~min})\end{array}$ & $17.5 \mathrm{~min}$
\end{tabular}

Table 9. Sample confirmation runs.

\begin{tabular}{l|c|c|c|c|c} 
Wavelength & PEG\% & UHT\% & $\begin{array}{c}\text { Experimental curing } \\
\text { time }\end{array}$ & $\begin{array}{c}\text { Prediction curing } \\
\text { time }\end{array}$ & $\begin{array}{c}\text { Percent Error } \\
(\%)\end{array}$ \\
\hline UV & 40 & 70 & 18.58 & 19.7 & $5.7 \%$ \\
\hline UV & 60 & 30 & 10.37 & 10.58 & $2 \%$ \\
\hline VIS & 60 & 30 & 122 & 133.24 & $8.4 \%$ \\
\hline VIS & 40 & 70 & 19.23 & 17.86 & $7.7 \%$
\end{tabular}

\subsubsection{Confirmation runs.}

In this study, four (4) samples were randomly selected with two (2) samples were UV cured, and the other two (2) samples were cured with VIS light. Table 9 shows the confirmation run in order to verify the observed value to compare with predicted value from the equation model were collected. The percent error result shows that the combined factor levels had a 
result of less than $10 \%$ error. It means that the difference was considered acceptable in this study as a limit set of less than $10 \%$ [20].

\section{Conclusions}

In conclusion, the used of VIS give another option to look into 3D printing application. It was observed that surface cured was smooth when used VIS as compared with UV wavelength in an optimal solution. For future studies, it is proposed to use UV and VIS light as a hybrid method in the curing process to further evaluate the performance with respect to the mechanical properties, for example, tissue engineering.

\section{Funding}

This research was funded by Universiti Teknologi Malaysia (UTM) and Research Management Center, UTM, under Fundamental Research Grant Scheme (FRGS) funding number 5F188 and the Collaborative Research Grant (CRG) funding number 08G22 \& $08 \mathrm{G} 32$.

\section{Acknowledgments}

Thank Universiti Teknologi Malaysia for the funding and provided facilities for this project

\section{Conflicts of Interest}

The authors declare no conflict of interest.

\section{References}

1. Borrello, J.; Nasser, P.; Iatridis, J.; Costa, K.D. 3D Printing a Mechanically-Tunable Acrylate Resin on a Commercial DLP-SLA Printer. Addit Manuf 2018, 23, 374-380, https://doi.org/10.1016/j.addma.2018.08.019.

2. Joo, H.; Cho, S. Comparative Studies on Polyurethane Composites Filled with Polyaniline and Graphene for DLP-Type 3D Printing. Polymers (Basel) 2020, 12, https://doi.org/10.3390/polym12010067.

3. Bagheri, A.; Jin, J.Y. Photopolymerization in 3D Printing. ACS Appl. Polym. Mater. 2019, 1, 593-611, https://doi.org/10.1021/acsapm.8b00165.

4. Gao, Y.; Xu, L.; Zhao, Y.; You, Z.; Guan, Q. 3D printing preview for stereo-lithography based on photopolymerization kinetic models. Bioact Mater 2020, 5, 798-807, https://doi.org/10.1016/j.bioactmat.2020.05.006.

5. De Santis, R.; Gloria, A.; Maietta, S.; Martorelli, M.; De Luca, A.; Spagnuolo, G.; Riccitiello, F.; Rengo, S. Mechanical and Thermal Properties of Dental Composites Cured with CAD/CAM Assisted Solid-State Laser. Materials (Basel) 2018, 11, https://doi.org/10.3390/ma11040504.

6. Arifin, N.; Sudin, I.; Ngadiman, N.H.A. Fabrication PEGDA/ANFs Biomaterial as 3D Tissue Engineering Scaffold by DLP 3D Printing Tecshnology. IJEAT 2019, 8, 751-758, https://doi.org/10.35940/ijeat.F7989.088619.

7. Park, S.A.; Lee, S.J.; Seok, J.M.; Lee, J.H.; Kim, W.D.; Kwon, I.K. Fabrication of 3D Printed PCL/PEG Polyblend Scaffold Using Rapid Prototyping System for Bone Tissue Engineering Application. J. Bionic Eng. 2018, 15, 435-442, https://doi.org/10.1007/s42235-018-0034-8.

8. Kwak, H.; Shin, S.; Lee, H.; Hyun, J. Formation of a keratin layer with silk fibroin-polyethylene glycol composite hydrogel fabricated by digital light processing 3D printing. J. Ind. Eng. Chem. 2019, 72, 232-240, https://doi.org/10.1016/j.jiec.2018.12.023.

9. Zhang, H.; Xia, J.Y.; Pang, X.L.; Zhao, M.; Wang, B.Q.; Yang, L.L.; Wan, H.S.; Wu, J.B.; Fu, S.Z. Magnetic nanoparticle-loaded electrospun polymeric nanofibers for tissue engineering. Mater. Sci. Eng. C-Mater. Biol. Appl. 2017, 73, 537-543, https://doi.org/10.1016/j.msec.2016.12.116.

10. Strongone, V.; Bartoli, M.; Jagdale, P.; Arrigo, R.; Tagliaferro, A.; Malucelli, G. Preparation and Characterization of UV-LED Curable Acrylic Films Containing Biochar and/or Multiwalled Carbon Nanotubes: Effect of the Filler Loading on the Rheological, Thermal and Optical Properties. Polymers 2020, 12, https://doi.org/10.3390/polym12040796.

11. Zhang, J.; Huang, D.; Liu, S.; Dong, X.; Li, Y.; Zhang, H.; Yang, Z.; Su, Q.; Huang, W.; Zheng, W.; Zhou, W. Zirconia toughened hydroxyapatite biocomposite formed by a DLP 3D printing process for potential 
bone tissue engineering. Mater Sci Eng C Mater Biol Appl 2019, 105, https://doi.org/10.1016/j.msec.2019.110054.

12. Lin, J.T.; Cheng, D.C.; Chen, K.T.; Liu, H.W. Dual-Wavelength (UV and Blue) Controlled Photopolymerization Confinement for 3D-Printing: Modeling and Analysis of Measurements. Polymers (Basel) 2019, 11, https://doi.org/10.3390/polym11111819.

13. Guerra, A.J.; Lara-Padilla, H.; Becker, M.L.; Rodriguez, C.A.; Dean, D. Photopolymerizable Resins for 3DPrinting Solid-Cured Tissue Engineered Implants. Curr. Drug Targets 2019, 20, 823-838, https://doi.org/10.2174/1389450120666190114122815.

14. Guerra, A.J.; Lammel-Lindemann, J.; Katko, A.; Kleinfehn, A.; Rodriguez, C.A.; Catalani, L.H.; Becker, M.L.; Ciurana, J.; Dean, D. Optimization of photocrosslinkable resin components and 3D printing process parameters. Acta Biomater. 2019, 97, 154-161, https://doi.org/10.1016/j.actbio.2019.07.045.

15. Zhu, J.; Zhang, Q.; Yang, T.; Liu, Y.; Liu, R. 3D printing of multi-scalable structures via high penetration near-infrared photopolymerization. Nat Commun 2020, 11, https://doi.org/10.1038/s41467-020-17251-z.

16. Zhou, R.C.; Jin, M.; Malval, J.P.; Pan, H.Y.; Wan, D.C. Bicarbazole-based oxalates as photoinitiating systems for photopolymerization under UV-Vis LEDs. J. Polym. Sci. 2020, 58, 1079-1091, https://doi.org/10.1002/pol.20199298.

17. Park, H.K.; Shin, M.; Kim, B.; Park, J.W.; Lee, H. A visible light-curable yet visible wavelength-transparent resin for stereolithography 3D printing. NPG Asia Mater. 2018, 10, https://doi.org/10.1038/s41427-0180021-x.

18. Quan, H.; Zhang, T.; Xu, H.; Luo, S.; Nie, J.; Zhu, X. Photo-curing 3D printing technique and its challenges. Bioact Mater 2020, 5, 110-115, https://doi.org/10.1016/j.bioactmat.2019.12.003.

19. Lee, R. Statistical Design of Experiments for Screening and Optimization. Chem. Ing. Tech. 2019, 91, 191200, https://doi.org/10.1002/cite.201800100.

20. Ngadiman, N.H.A.; Noordin, M.Y.; Idris, A.; Kurniawan, D. A review of evolution of electrospun tissue engineering scaffold: From two dimensions to three dimensions. Proc Inst Mech Eng H 2017, 231, 597-616, https://doi.org/10.1177/0954411917699021. 